\title{
Is black tea better for your teeth than acidic soft drinks?
}

\author{
Tooth surface pH during drinking of black tea by A. Simpson, L. Shaw, and A. J. Smith Br Dent J 2001; 190:374-376
}

\section{Objectives}

To investigate the composition of black tea in terms of its erosive potential. To determine the $\mathrm{pH}$ profile at the palatal surface of anterior and posterior sites of the dentition after drinking black tea.

\section{Methods}

Tea solution was analysed for its $\mathrm{pH}$ and anion composition to provide information on its acid content. A group of ten healthy subjects, aged 21-23 years were monitored for tooth surface $\mathrm{pH}$ on the palatal aspects of the maxillary anterior dentition and the maxillary molar dentition after drinking tea using a micro-pH electrode mounted on a vinyl splint.

\section{Results}

The $\mathrm{pH}$ of the tea solution was 4.9 and the major anions detected were oxalate and citrate. Tooth surface $\mathrm{pH}$ monitoring indicated that only small decreases in $\mathrm{pH}$ of less than $1 \mathrm{pH}$ unit were observed after drinking tea and the minimum mean $\mathrm{pH}$ reached was 5.45. Maximum decrease in $\mathrm{pH}$ was observed after 20-25 seconds and resting $\mathrm{pH}$ levels were restored within approximately 2 minutes after drinking.

\section{Conclusion}

The $\mathrm{pH}$ and anion profile of black tea are indicative of low acid composition. The very small $\mathrm{pH}$ decreases observed at the tooth surface after drinking tea indicate that it may be safely recommended as a substitute for more acidic drinks as a part of preventive measures for dental erosion.

\section{In Brief}

- Preventive advice should focus on reducing the consumption of acidic beverages and recommending safe alternatives

- Black tea has a low acid composition and its consumption leads to only small and short-lived decreases in $\mathrm{pH}$ at the tooth surface

- Further oral health benefits may accrue from drinking tea as a result of the appreciable fluoride content

- Alternative forms of presentation of tea, eg, iced tea or canned cold tea, may allow it to be successfully targeted at a broad range of the population

\section{Comment}

Sugared and acid soft drinks have been Simplicated in causing dental caries and erosion. Unfortunately, they are popular, heavily advertised, and consumed in large quantities by adolescents in particular. Water is an excellent drink but has little 'street cred'. Milk is desirable from the nutritional viewpoint and is safe for teeth, as long as sugar is not added. Tea and coffee have also been recommended as satisfactory drinks from the dental viewpoint, again, as long as no sugar is added. There has been research on and off over 50 years on the anti-cariogenic properties of tea but, until now, we have been ignorant of the acidity of tea as drunk in this country and whether it is likely to erode teeth. This makes this paper, by experts on erosion from Birming- ham Dental School, a valuable contribution to knowledge. It shows that although tea is acid, it is very weakly acid and contains only about $1 \%$ of the amount of citric acid found in fruit juice. They found that the fall in $\mathrm{pH}$ at the surface of teeth of young adult volunteers was small and brief, and unlikely to cause dental erosion. That is good news. It is possible to argue that these acids are chelators, which could remove calcium at more neutral $\mathrm{pH}$. Other in-vitro experiments could test this, but it is unlikely that this is important. It is also worth noting that the $\mathrm{pH}$ profile in-vivo was not compared with any other drink, although one suspects that the extent and duration of the fall in $\mathrm{pH}$ would have been much greater with other acid soft drinks.
The authors rightly discuss what could be added to tea - milk, sugar or lemon. Milk would be desirable, sugar definitely not, and lemon might depend on the quantity. They also draw attention to the fact that tea reduces absorption of dietary iron. Iron is a risk nutrient for some groups in this country and more so in developing countries. Advice in these countries is often that young children should avoid drinking tea with meals - if so, unsugared tea with or without milk, would make a good, dentally safe, between meal drink for children.

\section{A. Rugg-Gunn}

Professor, Newcastle Dental School 